\title{
Mapping the Preferences of Adult and Child Consumers for California-grown Mandarins
}

\author{
Tyler Simons ${ }^{1}$, Hanne Sivertsen, and Jean-Xavier Guinard \\ Department of Food Science and Technology, University of California, \\ Davis, One Shields Avenue, Davis, CA 95616
}

Additional index words. consumer testing, just-about-right scaling, descriptive analysis, adults, children

\begin{abstract}
Citrus consumers from Northern California-231 adults (ages 18-77 years) and 98 children (ages 8-12 years) — rated their overall liking (OL) and liking for appearance, flavor, and texture, as well as adequacy of sweetness, sourness, firmness, and juiciness for eight commercially available California mandarins and a tangelo. Descriptive analysis was performed on fruit from the same batch. Three adult and two child preference clusters were identified. Most of the adult and child consumers preferred samples that were high in sweetness, peelability, mandarin aroma, and firmness of fruit flesh. Sour fruit was substantially preferred by $23 \%$ of the adult consumers. Liking of appearance showed the lowest correlations with liking of flavor, texture, and OL. This work confirms past research on the necessity of sweet, sour, and peelable fruit for consumers. The findings presented here also suggest that consumer clustering can help to demystify research into preferences for mandarins and their hybrids.
\end{abstract}

Production of fresh citrus fruit begets a tremendous economic impact on the State of California, accounting for a total market value of more than $\$ 2.2$ billion per year [National Agricultural Statistics Service (NASS), 2017]. Fresh market mandarins in the United States are a \$570 million crop with California as the majority producer among the states, at $94 \%$ of production [National Agricultural Statistics Service (NASS), 2017]. Because of their desirability, ease of peeling, and favorable flavor, the market for mandarins is growing. There was a $10 \%$ increase in production volume since 2015 [National Agricultural Statistics Service (NASS), 2017].

Numerous sensory evaluation studies have been conducted on mandarins, mainly through the use of semi-expert or expert judges who evaluated sensory attributes, quality, and hedonic liking (Goldenberg et al., 2015; Hagenmaier, 2002; Obenland et al., 2009, 2011; Tietel et al., 2010). These studies have investigated flavor changes from fruit diversity (Goldenberg et al., 2014, 2015), preharvest effects (Mourão Filho et al., 2007), and postharvest treatments such as waxing (Hagenmaier, 2002; Tietel et al., 2010), storage time, and temperature (Obenland et al., 2011; Tietel et al., 2012). Although valuable, many studies fail to

\footnotetext{
Received for publication 23 Mar. 2018. Accepted for publication 13 May 2018.

This research was funded by the California Citrus Research Board (Project \#5200-150).

We thank Pauline Lestringant for her help with data analysis. We also thank Melissa Pellini for her work collecting the sugar and acid values.

${ }^{1}$ Corresponding author.E-mail: tjsimons@ucdavis. edu.
}

address perceptions of consumers with fruit that they are able to purchase. More studies are needed involving fruit that have been washed, waxed, and packed; a key detail which substantially modulates the flavor of the fruit (Davis and Hofmann, 1973; Hagenmaier, 2002; Obenland et al., 2011; Tietel et al., 2010).

Current regulations in California for $\mathrm{Na}$ vel oranges and mandarins differ. Mandarins are required to have a soluble solids content (SSC) to titratable acid (TA) ratio of at least 6:1, whereas Navel oranges are regulated by the California Standard (Ferguson and Grafton-Cardwell, 2014). The California Standard is derivative of the BrimA measurement which subtracts weighted TA from SSC (Ferguson and Grafton-Cardwell, 2014; Jordan et al., 2001). Both of these values are known to affect consumer liking (Goldenberg et al., 2015; Obenland et al., 2009; Tietel et al., 2012), but the concept of mandarin and citrus flavor is more complicated than that of SSC and TA (Miyazaki et al., 2012; Obenland et al., 2009; Tietel et al., 2011; Yu et al., 2017). Appearance, flavor, taste, and texture work together to create the sensory experience of a mandarin, which suggests that proper evaluation should use sensory panelists when possible.

Past work with consumer preference mapping has helped to elucidate the important sensory attributes that drive liking for many foods and beverages (Campbell et al., 2004; Carbonell et al., 2008; Daillant-Spinnler et al., 1996; Delgado and Guinard, 2011), often investigating consumer segmentation in tandem. Successful preference mapping requires targeting the correct group of users of the product (Lawless and Heymann, 2010). Today, mandarins are marketed strongly toward children and families. Halos ${ }^{\circledR}$ and Cuties ${ }^{\circledR}$ focus their advertising on families; the former promoting the tagline "Good Choice, Kid," whereas the later notes their product is for "little hands," "kid-sized," and "kid-friendly." Despite these slogans, no consumer studies have been published on children's liking of mandarins in California.

This study set out to characterize the sensory preferences of adult and child consumers living in the Davis and Sacramento area of Northern California with fruit that they might encounter in a typical purchasing situation. We hypothesized that consumer preferences for mandarins would be heterogeneous, with unique cluster preferences for specific sensory attributes. We also hypothesized that sweeter fruit, as opposed to more sour fruit, would be preferred based on past work (Goldenberg et al., 2015; Tietel et al., 2011).

\section{Materials and Methods}

Fruit samples. Eight samples of commercial mandarins and one tangelo $(500+$ pieces each) were obtained from a local wholesale grocery store and produce wholesalers. The fruit obtained came from the same pallet with all boxes bearing the same run number to ensure consistency. The fruit consisted of specified varieties, as seen in Table 1 . On reception, all samples were stored in a cold room at $5{ }^{\circ} \mathrm{C}$ and $85 \%$ humidity. To minimize sensory changes, all experiments were conducted within $10 \mathrm{~d}$ of acquiring the fruit. The fruit were removed from cold storage less than $1 \mathrm{~d}$ before testing to equilibrate them to room temperature.

The tangelo sample was included in all analyses as naïve consumers may not be aware that they are distinct from true mandarins. These fruits are also consumed in a similar manner to mandarins, i.e., peeled whole and eaten. In addition, this lineage presented an intriguing difference in sensory attributes in comparison with the other samples.

Descriptive analysis. A generic descriptive analysis that combined elements of the quantitative descriptive analysis and spectrum methods was used with six judges (four females, two males; ages 27-50 years) who had prior descriptive analysis experience. All panelists completed 10 training sessions before evaluation. The first two sessions involved term generation based on the sensory properties of mandarins purchased at local retail outlets. The following sessions focused on concept alignment of terms that were generated by the panelists, aided by the use of reference standards, to create a list of terms, as seen in Table 2. Many of the terms generated by the panelists reflect past work that has been performed on citrus fruit (Goldenberg et al., 2015; Kim et al., 2013; Miyazaki et al., 2012; Plotto et al., 2010). During training, judges used a sample ballot, which listed each of the terms adjacent to a $10-\mathrm{cm}$ line scale anchored at $1 \mathrm{~cm}$ indentations to limit end effects (Lawless and Heymann, 2010). For data collection, an 
Table 1. Commercial mandarin and tangelo samples tested. The fruit were stored at $5{ }^{\circ} \mathrm{C}$ and $85 \%$ relative humidity on reception. Once received, all samples were evaluated by consumer and descriptive analysis within $10 \mathrm{~d}$.

\begin{tabular}{|c|c|c|}
\hline Products & Date received & Dates tested by consumers \\
\hline Clementine (Clem 1) & 6 Jan. 2016 & 9-13 Jan. 2016 \\
\hline Clementine (Clem 2) & 8 Jan. 2016 & 9-13 Jan. 2016 \\
\hline Dancy Tangerine (Dancy) & 8 Jan. 2016 & 9-13 Jan. 2016 \\
\hline Owari Satsuma (Satsuma) & 8 Jan. 2016 & 9-13 Jan. 2016 \\
\hline Minneola Tangelo (Minneola) ${ }^{\mathrm{z}}$ & 3 Mar. 2016 & 6-13 Mar. 2016 \\
\hline W. Murcott (Murcott 1) $)^{\mathrm{z}}$ & 3 Mar. 2016 & 6-13 Mar. 2016 \\
\hline W. Murcott (Murcott 2) ${ }^{\mathrm{z}}$ & 3 Mar. 2016 & 6-13 Mar. 2016 \\
\hline W. Murcott (Murcott 3) & 3 Mar. 2016 & 6-13 Mar. 2016 \\
\hline W. Murcott (Murcott 4) ${ }^{z}$ & 3 Mar. 2016 & 6-13 Mar. 2016 \\
\hline
\end{tabular}

${ }_{\mathrm{z}}^{\mathrm{z}}$ dicates tested for sugar and acid content.

electronic ballot was designed using FIZZ (Biosystèmes, Couternon, France). Under white light, the judges were presented with fruit in whole form and instructed to evaluate the exterior attributes. Following this, the panelists peeled the fruit to evaluate the aroma and peel characteristics. They continued by rating the taste, flavor, and texture of the fruit. Unsalted crackers (Mondelez, East Hanover, NJ) and water were provided to cleanse their palates between samples. The samples, coded using randomized three digit codes, were evaluated in triplicate. Presentation order of the samples was randomized using a William's Latin square (Williams, 1949) design provided by the FIZZ software. Performance of the panel, including discrimination ability, reproducibility, and concept alignment, was checked before evaluation to ensure panel readiness.

Sugar and acid measurements. Eight mandarins of each sample from the March tasting (W. Murcott and Minneola samples) were separately juiced into replications. Fifty milliliters of the juice from each of the eight replications was then placed into a $60 \mathrm{~mL}$ plastic cup, capped, and refrigerated at $3{ }^{\circ} \mathrm{C}$ for up to $1 \mathrm{~d}$. Samples of juice were analyzed for SSC using a LTD Refractometer 110 (Bellingham + Stanley, Kent, UK). The $\mathrm{pH}$ was measured with an Orion 5-Star Plus $\mathrm{pH}$ meter (Thermo Fisher Scientific, Waltham, MA). Samples of the juice were also used to measure TA by the titration of $0.1 \mathrm{M} \mathrm{NaOH}$ to the end point of $\mathrm{pH} 8.2$ using a Mettler Toledo DL50 titrator (Mettler Toledo, Columbus, $\mathrm{OH})$. The SSC/TA ratio was calculated by dividing the SSC concentration by the TA concentration. The BrimA value was also calculated for each of the eight replication samples using the equation:

$$
\mathrm{Brim} \mathrm{A}=\left(\mathrm{SSC}-4^{*} \mathrm{TA}\right) .
$$

Consumers. Adults and children (ages 812 years) from the local (Davis, Woodland and Sacramento, CA) community were recruited for the tests. Potential participants were screened for appropriate age, lack of food allergies, and frequency of citrus consumption (at least once or twice per month, while is season). The age of the children was decided based on cognitive abilities required to use hedonic scales, intensity scales, and other sensory measures (Guinard, 2000). Children were accompanied by a parent/ guardian at all times, but seated at their own individual booth.

The consumer tasting sessions took place in the Silverado Vineyards Sensory Theater of the Robert Mondavi Institute for Wine and Food Science at the University of California, Davis, across two sessions, one in January and one in March. In the first session (January), the consumers tasted the Clementine, Satsuma, and Tangerine samples. They evaluated the Murcott and Tangelo samples in the second session (March). Tasting dates and their relation to fruit acquisition are shown in Table 1. In total, 231 adults and 98 children completed the tasting. They tasted five samples on each occasion for a total of 10 samples, 9 unique samples and 1 blind replication. The blind replication was included in the experimental design to keep the number of samples consistent between sessions and was removed for all analyses. The consumers were separated by booth dividers to prevent interaction with their neighbors. Each consumer was given a ballot with a front and back page for the evaluation of each sample, napkins, water and crackers (palate cleaners), and a plastic knife (for peeling, if they desired). The fruit was served whole, in clear, $4 \mathrm{oz}$ soufflé cups. The consumers were informed that they would be evaluating samples of mandarins from California and instructed on how to proceed through the ballot and survey. The consumers were briefed on the anonymity and voluntary nature of the study. All consumers consented to participate in the tasting. Consumers received a gift card ranging from $\$ 5$ to $\$ 10$ based on their age for their participation in the study. This study was approved for the use of human subjects by the Institutional Review Board of the University of California, Davis (ID 821014-1).

Exit survey. The adults participating in the study completed an online questionnaire between the tasting in January and March. This questionnaire aimed to collect information on their demographics, consumption habits, and psychographics. The survey was hosted by Survey Monkey (Palo Alto, CA). The survey asked a range of questions to the consumers including ethnicity, household income, number of children (if applicable), frequency of citrus and produce consumption, and questions regarding food neophobia. Some of these questions included familiarity with nutrition, adherence to diets, and personal histories with ethnic food. These questions were asked to separate consumer by their eating habits as has been effective in past research (Pliner and Hobden, 1992).

Ballots. Adult consumers rated their degree of liking on the 9-point hedonic scale (Peryam and Pilgrim, 1957) for appearance, internal color, OL, flavor, and texture, as well as the adequacy of sweetness, sourness, firmness, and juiciness on a 5-point justabout-right (JAR) scale (Rothman and Parker, 2009). Child consumers rated their liking of the appearance, taste, and texture of the fruit on a smaller, 7-point hedonic scale with cartoon faces (Guinard, 2000) and the adequacy of the sweetness, sourness, firmness, and juiciness of the fruit on a 3-point JAR scale from "too low" to "too high," with "just right" as the midpoint. Both adults and children rated the difficulty of peeling the fruit on a 5-point and 3-point scale, respectively.

Data analysis. All data analysis was performed using R (R Core Team, Vienna, Austria). The level of alpha was set at 0.05 for all statistical parameters. A full-model, threefactor analysis of variance (ANOVA) was performed for each descriptive attribute. The three factors assessed were judges, replications, and products along with their two-way interactions using a pseudo-mixed model approach (King et al., 2012). Following the ANOVA, a Fisher's least significant difference was applied to the product means. Principal components analysis was performed on the covariance matrix of the attributes, which were found to differ by ANOVA.

For the consumer data, univariate statistics, including means, standard deviation, and standard error, were performed on the hedonic questions. Penalty analysis, or meandrop analysis (Rothman and Parker, 2009), was performed on the JAR scales for all modalities in comparison with OL (adults) or liking of taste (children). In case of missing values, data were imputed using the rounded average score for the product. Correlations were drawn using Pearson's product-moment correlation. For preference clustering, all values for OL and for liking of taste (for adults and children, respectively) were scaled to mean of 0 and standard deviation of 1 to prevent clustering based on scale usage differences. Following the scaling, a Euclidean distance matrix was computed between consumers. Consumers were then clustered according to Ward's Method (Qannari et al., 1997). A two-way ANOVA was performed and a significant cluster by product interaction validated the clusters. Consumer preferences were modeled with the descriptive analysis measurements using a PLS2 regression model (Martens and Martens, 1986). Chi-square tests were performed on the consumer segments with respect to their answers on the exit survey to determine differences in demographics, psychographics, and citrus 
Table 2. Categories, descriptors, definitions, and references used for descriptive analysis of the mandarin/tangelo samples. Terms were generated by the panel on a variety of commercially available mandarins during the weeks before testing.

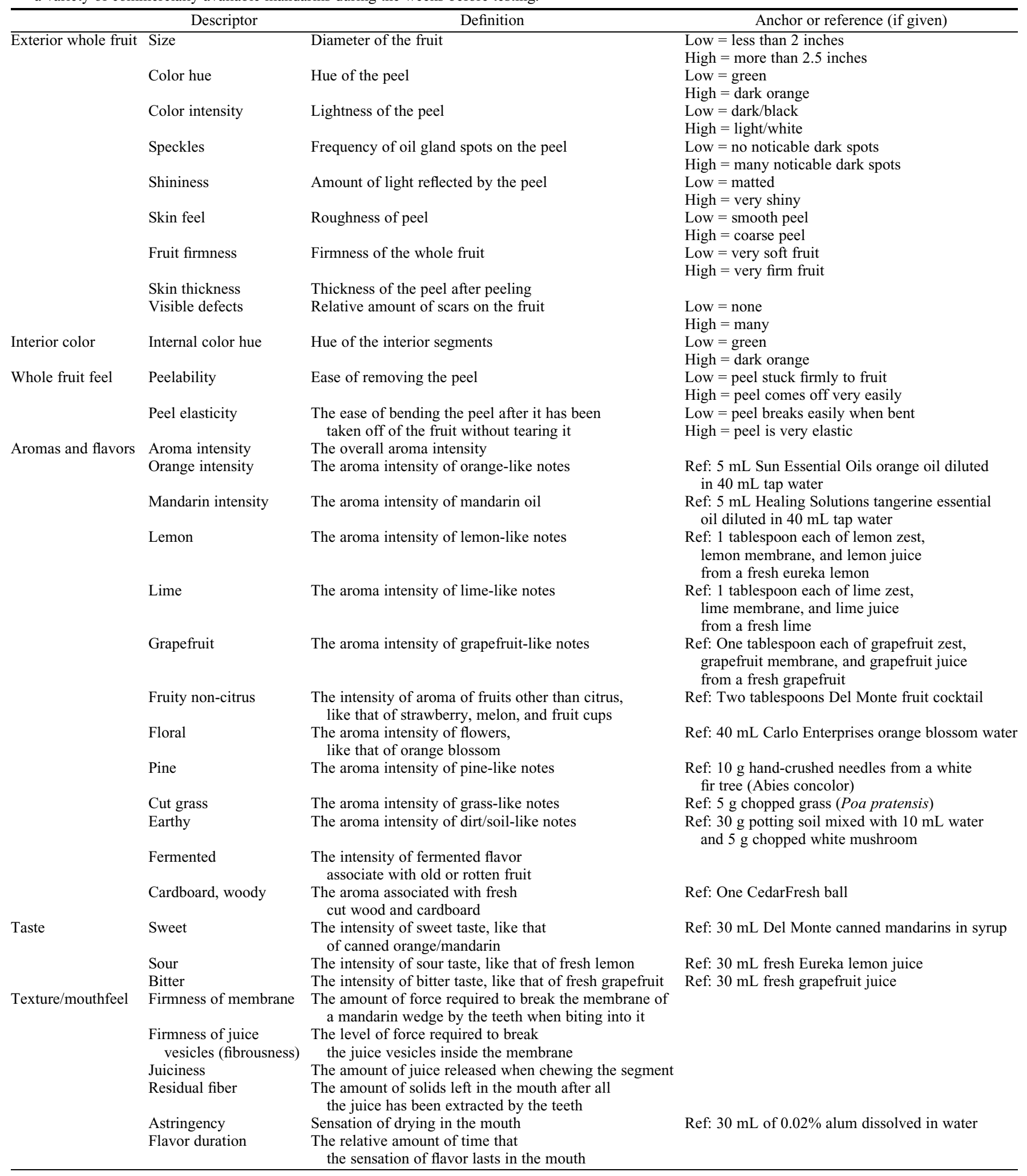

consumption habits. Chi-square tests were also performed to compare JAR ratings.

\section{Results}

Many descriptive attributes differed significantly among the tested fruit, including appearance, peel, aroma, taste, and texture attributes (Table 3). The flavor differences between the samples are quite clear. The Minneola sample, the only tangelo, was the most sour, and highest in lemon and lime flavors. The Clementine and Murcott samples had firmer textures and were sweeter than the Minneola. The SSC and TA values for the March samples are shown in Table 4. This table shows that the Minneola had the highest SSC, the highest TA, and the lowest SSC/TA ratio. The Murcott samples differed both in sugar and acid levels. Murcott 1 and 2 had higher SSC than the other two samples and Murcott 1 was more acidic.

The adult consumers liked nearly all aspects of the fruit. Their liking ratings for 
Table 4. Soluble-solid content (SSC), $\mathrm{pH}$, titratable acidity (TA), and BrimA measurements for the March mandarins. Values represent the average of eight replications for each sample. BrimA is shown here as $(\mathrm{SSC}-4 \times \mathrm{TA})$

\begin{tabular}{llllrl}
\hline Sample & SSC & pH & TA & SSC/acid & BrimA \\
\hline Minneola & $13.20 \mathrm{a}^{\mathrm{z}}$ & $3.19 \mathrm{c}$ & $1.62 \mathrm{a}$ & $8.20 \mathrm{c}$ & $6.71 \mathrm{c}$ \\
Murcott 1 & $12.46 \mathrm{a}$ & $3.49 \mathrm{~b}$ & $1.05 \mathrm{~b}$ & $12.31 \mathrm{~b}$ & $8.27 \mathrm{~b}$ \\
Murcott 2 & $12.96 \mathrm{a}$ & $3.69 \mathrm{a}$ & $0.81 \mathrm{c}$ & $16.70 \mathrm{a}$ & $9.74 \mathrm{a}$ \\
Murcott 3 & $10.11 \mathrm{~b}$ & $3.63 \mathrm{ab}$ & $0.85 \mathrm{c}$ & $12.12 \mathrm{~b}$ & $6.73 \mathrm{c}$ \\
Murcott 4 & $10.74 \mathrm{~b}$ & $3.76 \mathrm{a}$ & $0.69 \mathrm{c}$ & $15.90 \mathrm{a}$ & $7.96 \mathrm{~b}$ \\
\hline
\end{tabular}

${ }^{\mathrm{z}}$ Columns sharing a letter are not significantly different $(P \leq 0.05)$ by Fisher's least significant difference test.

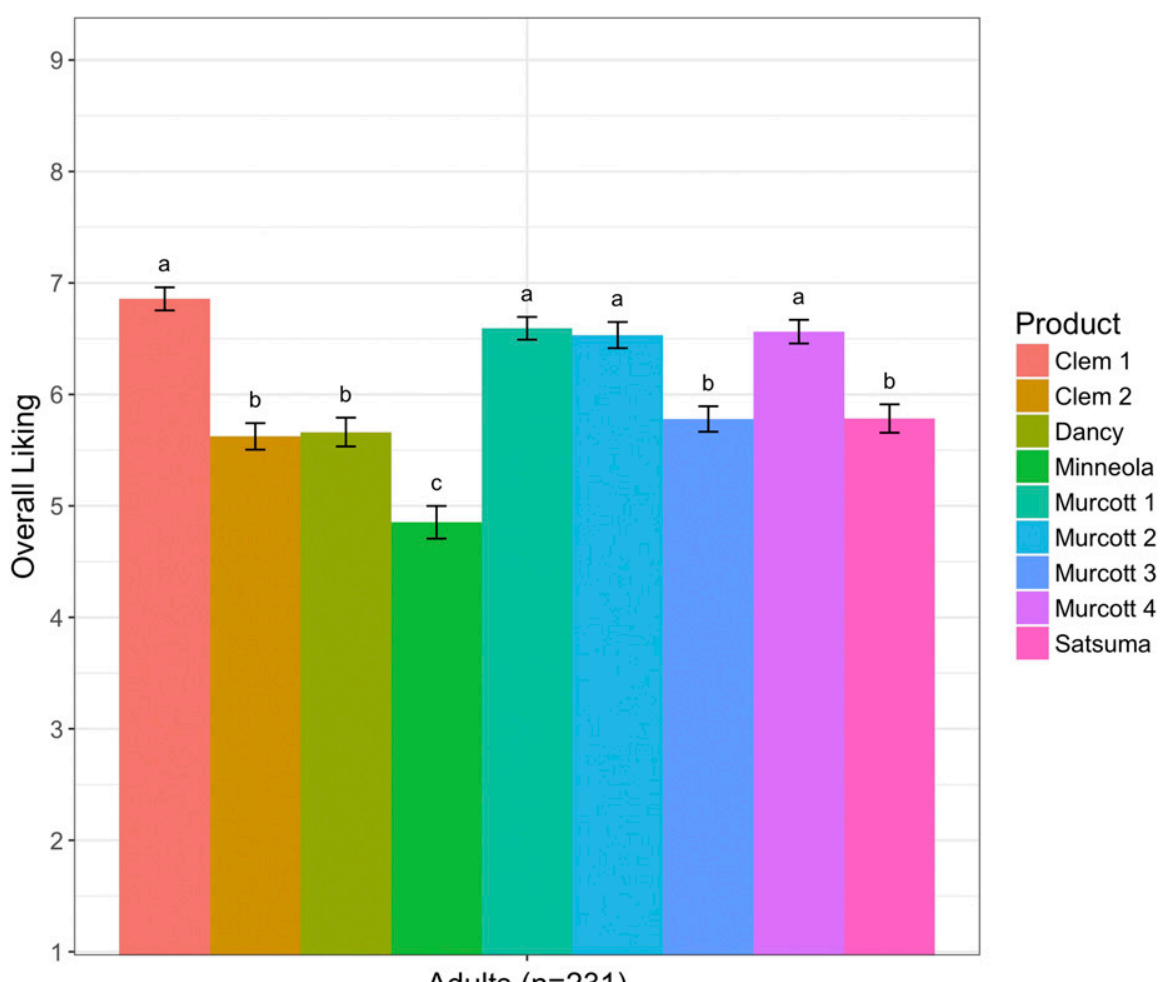

Adults $(n=231)$

Fig. 1. Overall liking ratings for all of the tested fruit samples by adult consumers, where $1=$ "Dislike extremely" and $9=$ "Like extremely." Products not sharing a letter are significant $(P \leq 0.05)$ by Fisher's least significant difference test.

all modalities were above "neither like nor dislike" for all samples (data not shown), except for the Minneola, which was rated "neither like nor dislike" for liking of flavor, texture, and OL. OL ratings for the adults as a group are shown in Fig. 1. The adult-rated modalities were significantly correlated. The highest correlations were between OL and flavor $(r=0.89, P \leq$ $0.05)$, followed by OL and texture $(r=$ $0.71, P \leq 0.05)$. Liking of appearance and the other modalities constituted the weakest correlations $(0.34-0.40, P \leq 0.05)$. Specific attribute ratings measured by JAR scaling, in which the consumers rated their liking of attribute intensities on a bimodal scale, corroborated the differences as found by the descriptive panel, as shown in Table 5. More than half of the adult consumers found Clem 1 and Murcott 1, 2, and 4 samples to be "just about right" in terms of sweetness, whereas most of the other consumers felt the samples were "not quite sweet enough." For sourness, the Minneola and Satsuma samples were frequently marked as either "somewhat too sour/tart" or "much too sour/tart" and Clem 1 and Murcott 1, 2, and 4 were "just about right." For the most part, the levels of juiciness and firmness of the fruit were appropriate. The Minneola may have been "too juicy," as it was rated this way by $43 \%$ of the adult consumers, much more than any other sample.

The JAR ratings by each consumer were compared with their OL ratings and a "mean drop" was calculated. This value represents the penalty of an attribute of inadequate strength on the OL of the fruit. These values are shown in Fig. 2. Too little sweetness was marked nearly $50 \%$ of the time and carried a high penalty of more than 2 points on the 9point hedonic scale. This means that on average, fruit that was "JAR" in sweetness level performed two hedonic points better, a substantial margin. Too much sourness, although marked less frequently, carried an even higher penalty of nearly 2.25 hedonic 
Table 5. Proportions of just-about-right (JAR) ratings of mandarin and tangelo samples as rated by the adult consumers. The consumers were given one entire fruit and asked to evaluate it for hedonic and degree of intensity for sweetness, sourness, firmness, and juiciness on a 5-point scale. Ratings of 1 and 2 have been combined to "Too little," whereas ratings of 4 and 5 have been combined to "Too much."”

\begin{tabular}{|c|c|c|c|c|c|c|c|c|c|c|}
\hline Modality & Rating & Clem 1 & Clem 2 & Dancy & Minneola & Murcott 1 & Murcott 2 & Murcott 3 & Murcott 4 & $\overline{\text { Satsuma }}$ \\
\hline & Too little & 0.29 & 0.58 & 0.46 & 0.65 & 0.39 & 0.27 & 0.65 & 0.42 & 0.65 \\
\hline \multirow[t]{3}{*}{ Sweetness* } & JAR & 0.67 & 0.37 & 0.45 & 0.32 & 0.55 & 0.61 & 0.32 & 0.52 & 0.28 \\
\hline & Too much & 0.05 & 0.05 & 0.10 & 0.03 & 0.06 & 0.13 & 0.03 & 0.06 & 0.06 \\
\hline & Too little & 0.15 & 0.47 & 0.52 & 0.04 & 0.24 & 0.34 & 0.25 & 0.29 & 0.16 \\
\hline \multirow[t]{3}{*}{ Sourness* } & JAR & 0.69 & 0.45 & 0.44 & 0.29 & 0.61 & 0.57 & 0.45 & 0.59 & 0.40 \\
\hline & Too much & 0.16 & 0.08 & 0.04 & 0.67 & 0.16 & 0.10 & 0.30 & 0.12 & 0.44 \\
\hline & Too little & 0.03 & 0.13 & 0.35 & 0.53 & 0.09 & 0.06 & 0.06 & 0.11 & 0.58 \\
\hline \multirow[t]{3}{*}{ Firmness* } & JAR & 0.74 & 0.68 & 0.50 & 0.36 & 0.81 & 0.72 & 0.76 & 0.78 & 0.40 \\
\hline & Too much & 0.23 & 0.19 & 0.15 & 0.11 & 0.10 & 0.22 & 0.18 & 0.11 & 0.02 \\
\hline & Too little & 0.30 & 0.44 & 0.24 & 0.06 & 0.19 & 0.32 & 0.38 & 0.20 & 0.12 \\
\hline \multirow[t]{2}{*}{ Juiciness* } & JAR & 0.67 & 0.53 & 0.60 & 0.50 & 0.75 & 0.66 & 0.61 & 0.75 & 0.69 \\
\hline & Too much & 0.03 & 0.03 & 0.16 & 0.43 & 0.06 & 0.02 & 0.00 & 0.05 & 0.19 \\
\hline
\end{tabular}

${ }^{\mathrm{z}}$ Attributes marked by $*$ are significant $(P \leq 0.05)$ by $\chi^{2}$ test. The test was performed on the distribution of all ratings then combined.

points. To these consumers, the textural attributes were markedly less important than those of sweetness and sourness. It is also possible that the magnitude of difference for textural attributes between the fruit was not large. The children showed a similar penalty trend to the adults (data not shown). They provided a stronger penalty for "too little sweetness" at just more than 2.25 hedonic points and a weaker penalty for "too much sourness" at just less than 2 hedonic points. However, these penalties should be noted as stronger than the adults because of the shorter scale used by the children (7-point instead of the 9-point scale for the adults).

The adults were clustered according to their OL ratings, which means that consumers who provided similar preferences among the products were placed into groups through a method called agglomerative hierarchical clustering. Three consumer segments were found consisting of 53, 98, and 80 consumers for clusters 1,2 , and 3 , respectively. Cluster mean liking ratings, as shown in Fig. 3, revealed large discrepancies in comparison with the average ratings of all adults (Fig. 1), a fact most notable with the Minneola, Satsuma, and Dancy samples. The first cluster liked the Minneola sample the most and rated it higher than any other cluster. The other two clusters rated this fruit as "dislike slightly." In addition, cluster 1 also disliked Clem 2 and Dancy, with similar ratings to cluster 2. Cluster 2 disliked the Satsuma. Adult cluster 3 liked the fruit more overall, but showed the strongest dislike for the Minneola.

In addition to their heterogenous preferences, the consumer clusters also used the JAR scales differently, as shown in Table 6 . The first cluster showed a drastic difference in ratings for sourness across all of the products, rating the products as "not sour enough" $42 \%$ of the time, compared with $25 \%$ and $21 \%$ for the other two clusters. In addition, these consumers rated the fruit as "too sour" only $7 \%$ of the time, compared with $28 \%$ and $26 \%$ for the other consumers.

The children showed a similar pattern to the adults in terms of their liking of taste, as shown in Fig. 4. Their lowest ratings were given to Minneola, Satsuma, and Murcott 3. Their favorite samples were Clem 1 and

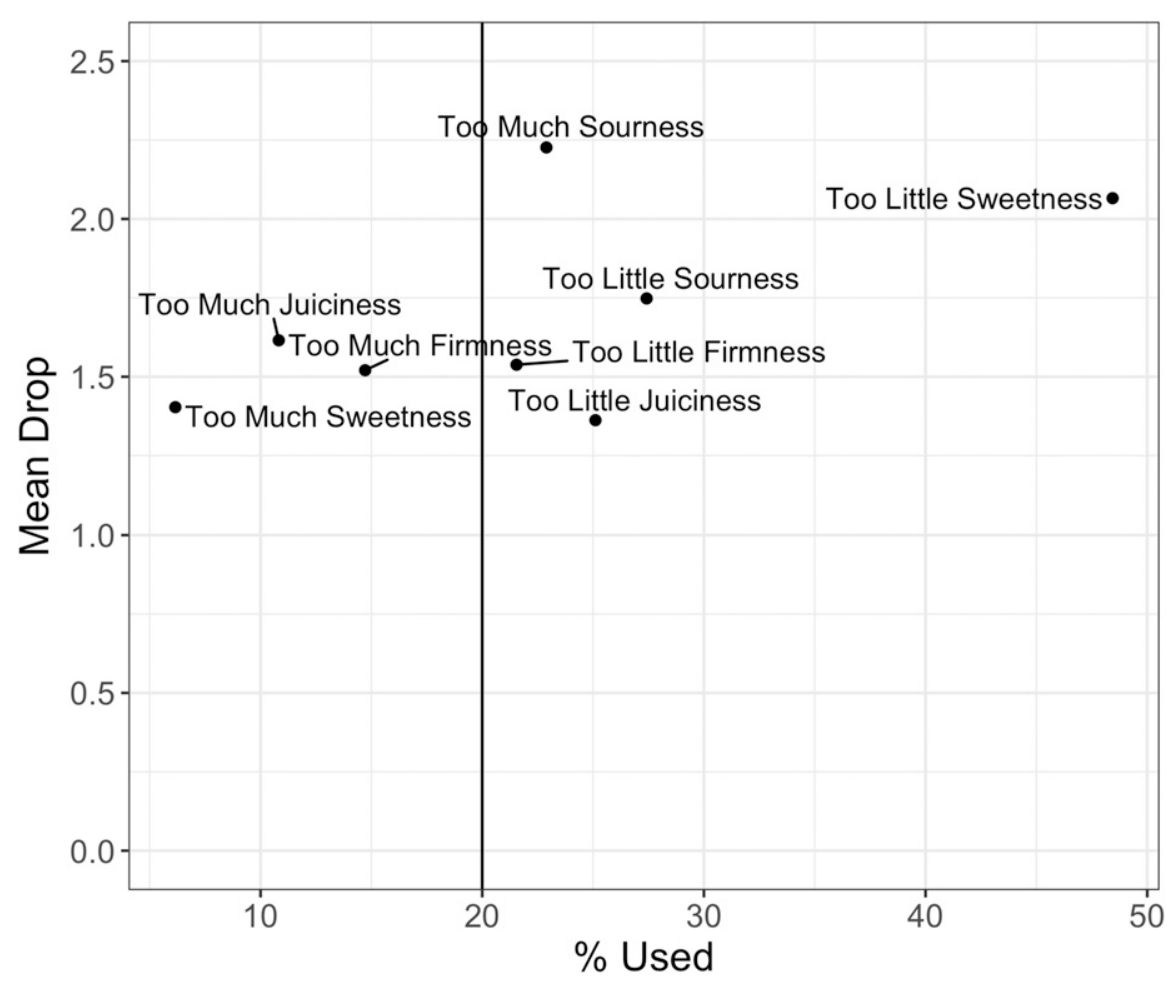

Fig. 2. Penalty of suboptimal attribute intensities for adults on overall liking (OL). The just-about-right (JAR) ratings for each fruit were compared with their OL scores. An average difference between liking scores for fruit with nonideal JAR and JAR ratings was calculated. Mean drop represents the average decrease in OL because of a lower than ideal ("Too little") or higher than ideal ("Too much") JAR rating across all of the fruit.

Murcott 1. Similar to the adults, there was a low correlation between the children's liking for taste and liking for appearance. From their JAR ratings, the children found Minneola, Murcott 3, and Satsuma to be too sour (data not shown), in similar fashion to the adults (Table 5). The Minneola was the most intense; $63 \%$ of the children marked this sample as too sour.

The children were clustered into two groups, containing 66 and 32 children based on their preferences. Preferences for fruit between child clusters are shown in Fig. 5 . Child cluster 1 was much more accepting of the Minneola sample, similar to a combination of adult clusters 1 and 2. Child cluster 2 was strongly driven away from the Minneola sample, similar to adult cluster 3. Other differences in the children clusters included their use of JAR ratings. Overall, child cluster 1 showed significantly $(P \leq 0.05)$ more desire for sourness with $24 \%$ of their ratings marked as "not sour enough," compared with only $16 \%$ by child cluster 2 (data not shown).

The relation between descriptive analysis data and adult consumer liking ratings was examined by PLS regression, where the descriptive attributes and the consumer cluster preferences are compared (Figs. 6 and 7 for the adults and children, respectively). In these figures, objects that are closer are more 


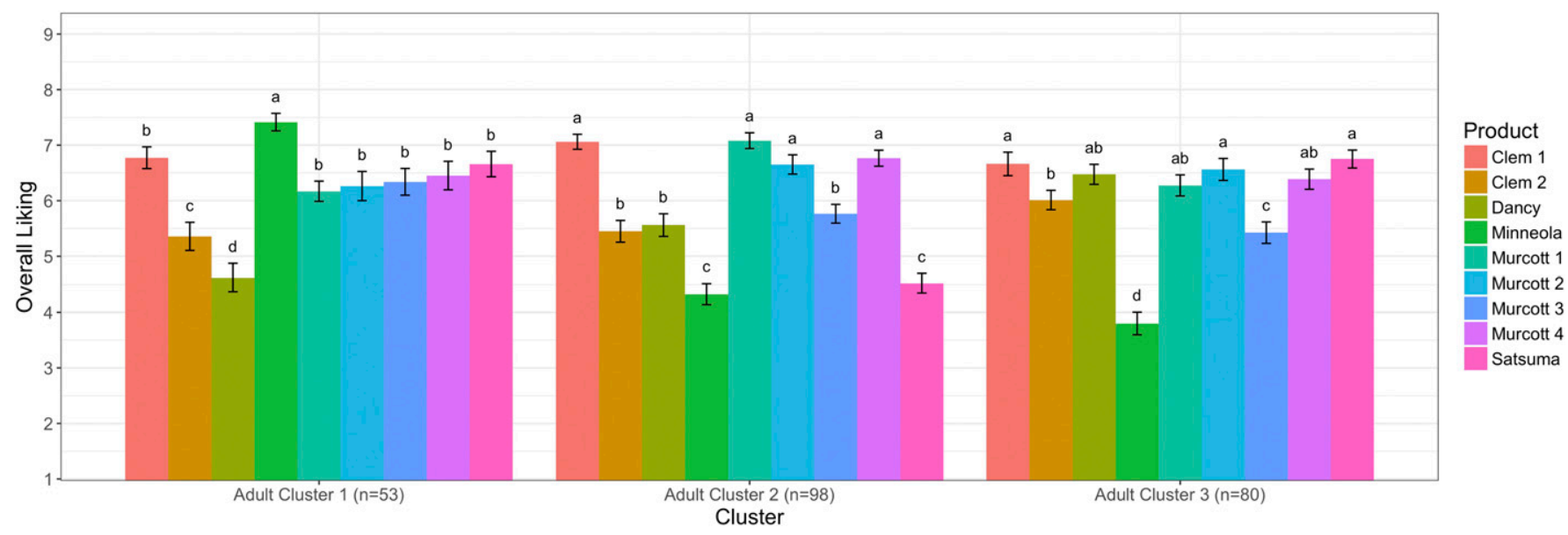

Fig. 3. Adult overall liking (OL) by cluster for each mandarin/tangelo sample. Adults were clustered based on their preferences using Ward's agglomeration method and validated through analysis of variance. Numbers correspond to the 9-point hedonic scale, where $1=$ "Dislike extremely" and $9=$ "Like extremely." Columns within a product category that share the same letter are not significantly different $(P \leq 0.05)$ by Fisher's least significant difference test.

Table 6. Proportion of adult just-about-right (JAR) ratings by cluster for sweetness and sourness of all mandarin and tangelo samples. The consumers were given one whole fruit to evaluate hedonic liking and JAR rating. Ratings of 1 and 2 and 3 and 4 have been combined into "Too little" and "Too much," respectively. $^{\mathrm{z}}$

\begin{tabular}{llccc}
\hline & JAR rating & Cluster 1 $(n=53)$ & Cluster 2 $(n=98)$ & Cluster 3 $(n=80)$ \\
\hline \multirow{3}{*}{ Sweetness* } & Too little & 0.42 & 0.51 & 0.49 \\
& JAR & 0.49 & 0.43 & 0.46 \\
& Too much & 0.09 & 0.06 & 0.05 \\
Sourness* & Too little & 0.42 & 0.25 & 0.21 \\
& JAR & 0.51 & 0.47 & 0.53 \\
& Too much & 0.07 & 0.28 & 0.26 \\
\hline
\end{tabular}

${ }^{\mathrm{z}}$ Attributes marked by $*$ are significant $(P \leq 0.05)$ by $\chi^{2}$ test. The test was performed on the distribution of all ratings then combined.
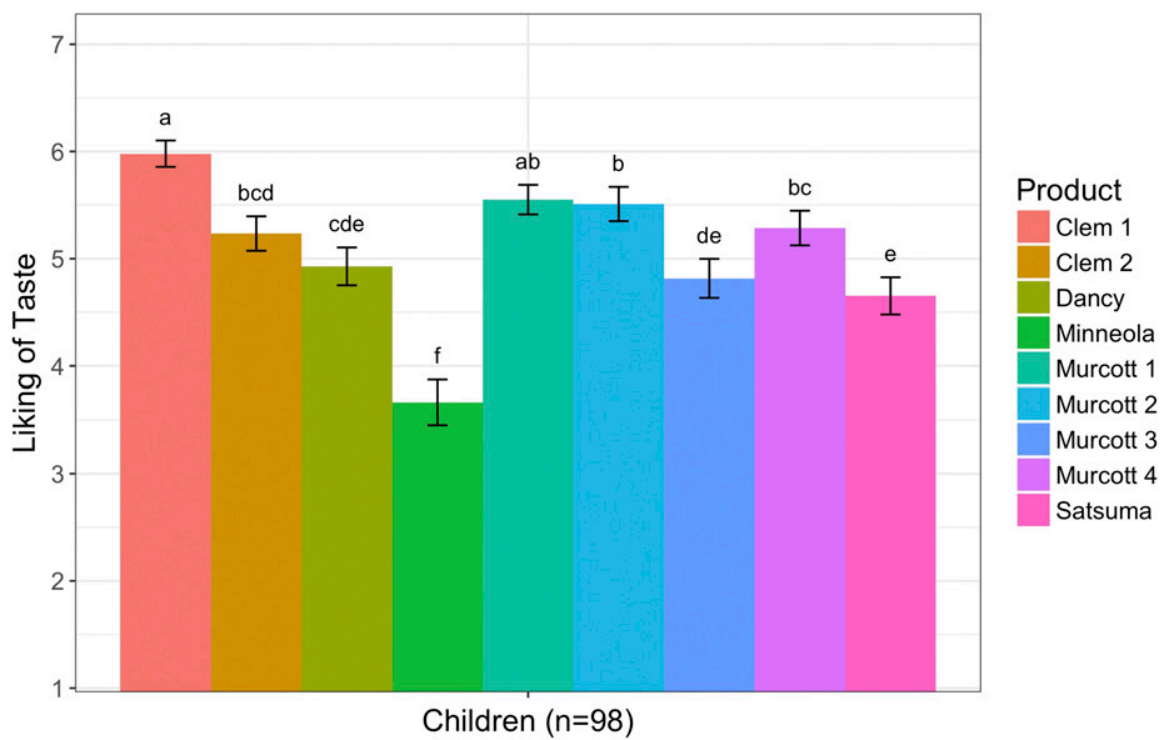

Fig. 4. Liking of taste ratings for all of the tested fruit samples by child consumers, where $1=$ "I hate it" and $7=$ "I love it." Products not sharing a letter are significant $(P \leq 0.05)$ by Fisher's least significant difference test.

correlated. Circles, triangles, and squares represent descriptive attributes, consumer clusters, and products, respectively. For example, Fig. 6 shows that the Minneola sample is well described by lime flavor, astringency, lemon flavor, bitterness, and sourness. The high in sourness, lemon and lime flavors, bitterness, and astringency. The second cluster preferred samples with higher textural firmness, darker interior color, and mandarin aroma. The third cluster preferred the samples that were sweet and easy to peel. For the children (Fig. 7), findings were similar to the second and third clusters of the adults. Most of the children preferred the samples that were more balanced in flavor, with high mandarin aroma, sweetness, and textural firmness.

The exit survey taken by the adults revealed information about their habits as clusters and as a group. No demographics or psychographics, including questions about food neophobia, were consistent to separate the clusters, but the groups differed in their consumption of orange juice. Adult cluster 1 drank orange juice much less frequently than the other two adult clusters. One hypothesis for this is that juice may be too sweet for these consumers. This product may appeal more to them if it came with higher acidity.

As a group, the consumers ate citrus very frequently, with $83 \%$ of them consuming the fruit at least two to three times per week. Many obtained their fruit from the grocery store $(89 \%)$, farmer markets $(49 \%)$, and wholesale retailers (37\%). Interestingly, $80 \%$ of the consumers felt that the quality of citrus fruit is highly variable and nearly $24 \%$ of them were often disappointed in the fruit they bought.

\section{Discussion}

The use of a trained descriptive analysis panel to evaluate the organoleptic properties of mandarins provided insight into the sensory properties of the fruit. The panelists identified 34 attributes that differed among cultivars and producers of mandarins, of which 20 attributes were found to differ in the fruit tested by the consumers. The attributes that were found to not be significant included attributes that either did not differ between the groups of tested fruit or their 


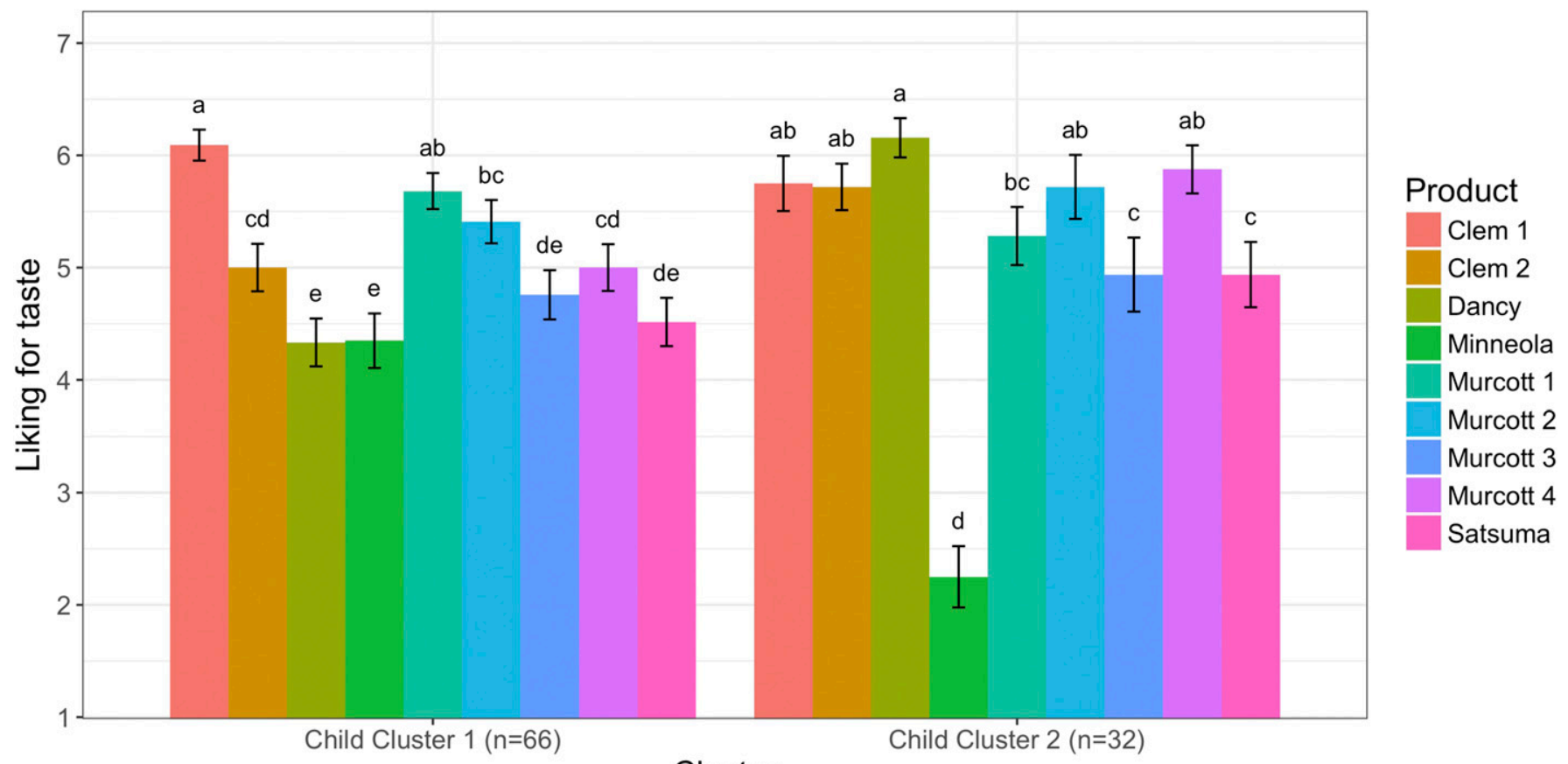

\section{Cluster}

Fig. 5. Child overall liking by cluster for each mandarin/tangelo sample. Children were clustered based on their preferences using Ward's agglomeration method and validated through analysis of variance. Numbers correspond to the 7-point hedonic scale, where $1=$ "I hate it" and $9=$ "I love it." Columns within a product category that share the same letter are not significantly different $(P \leq 0.05)$ by Fisher's least significant difference test.

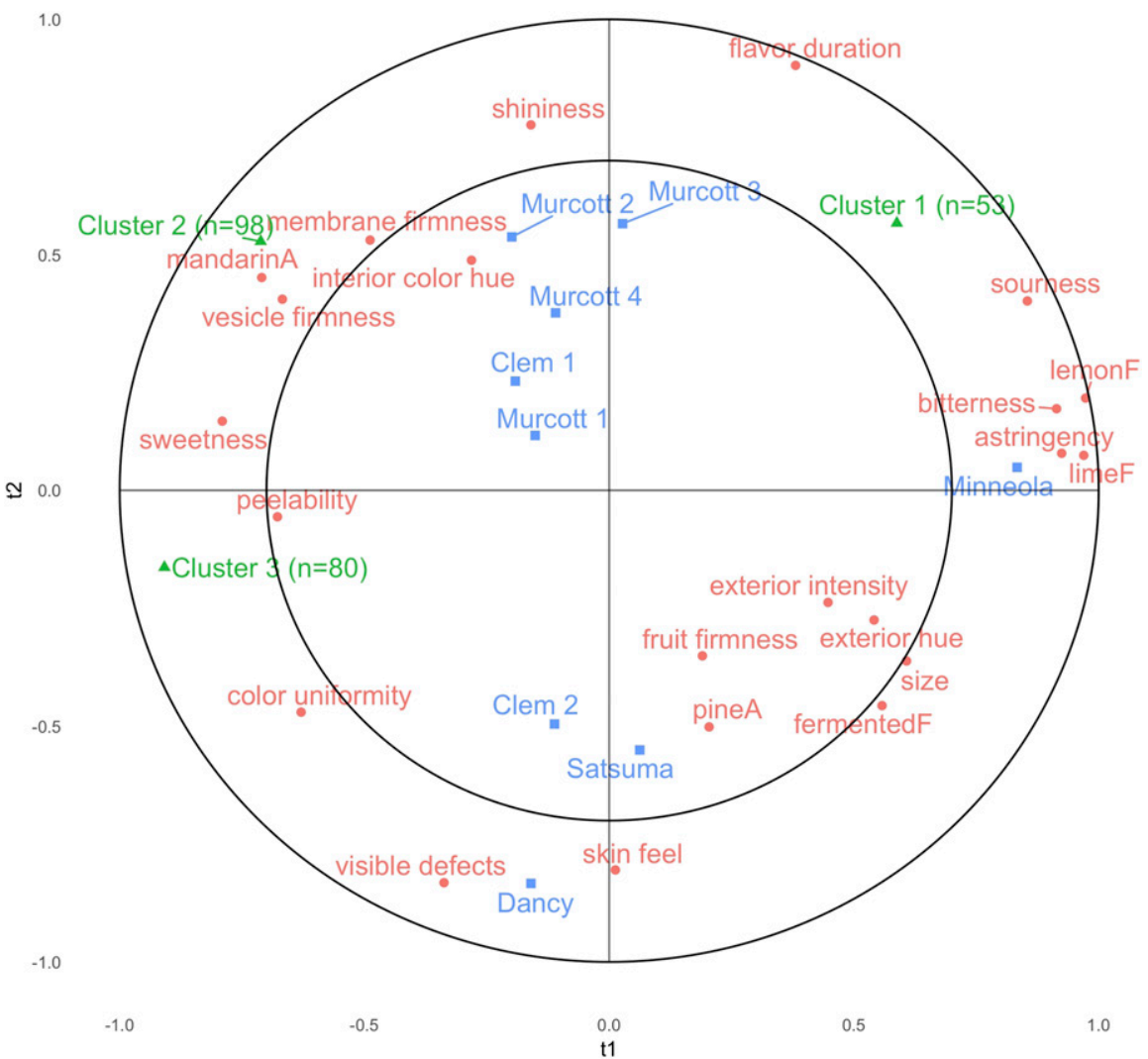

Fig. 6. PLS regression of adult overall liking with descriptive analysis attributes. Adult clusters, descriptive attributes, and products are shown as triangles, circles, and squares, respectively. Descriptive attributes and adult clusters were used as the independent and dependent variables, respectively. Objects located closer together on the plot are more correlated. $R^{2} Y=39 \%, 23 \% ; R^{2} X=57 \%, 21 \%$.

values were not agreed upon by the trained tasters. The ratings from the descriptive panel, paired with consumer liking values, showed that no mandarin is "one size fits all." Consumer preferences for mandarins covered a broad range of attributes but rely mainly on flavor and texture, as shown in Figs. 6 and 7.

The three clusters of adult consumers showed preferences of unique attributes with respect to the tested fruit. The first adult cluster clearly preferred the sour samples; the Minneola was their favorite, as shown in Fig. 3. This group not only rated this sample high but also rated it higher than any other cluster-product rating. They showed surprising preferences, characterized by fruit that are higher in astringency, bitterness, and lemon/lime character (Fig. 6). Although likely negative traits by themselves, the astringency and bitterness may merely be tolerated by these consumers in cluster 1 because of the association with acidity. However, ratings from overall JAR sourness (Table 6) suggested that these consumers could be specifically targeted through words such as "tart," as they rated samples mostly as "not sour enough." At only $23 \%$ of the consumer population, adult cluster 1 was the minority. The other $77 \%$ of consumers and nearly all children, however, preferred fruit with higher mandarin aroma, sweetness, and peelability (Figs. 6 and 7). These consumers did not prefer fruit that were characterized as bitter, sour, fermented, pine-like, or astringent.

For the children, sweetness was a crucial component of the liking. Both of the child clusters were driven toward the sweeter fruit (Fig. 7), a finding that is in agreement with the past research (De Graaf and Zandstra, 1999; Desor et al., 1975; Kühn and Thybo, 2001; Zandstra and de Graaf, 1998). For the second cluster of children, their lowest ratings went to the samples that were rated more 


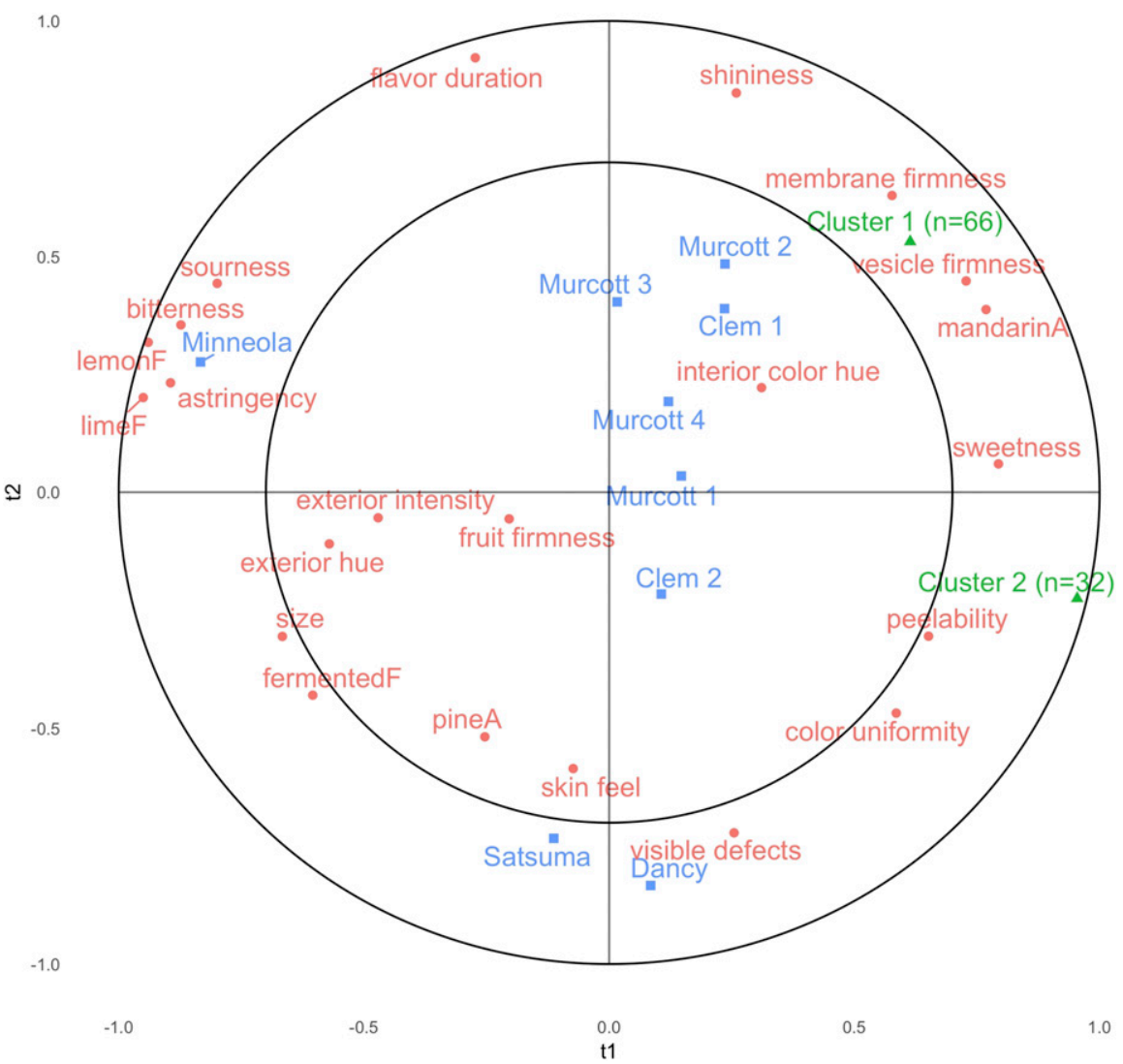

Fig. 7. PLS regression of child "liking of taste" scores with descriptive analysis attributes. Child clusters, descriptive attributes, and products are shown as triangles, circles, and squares, respectively. Descriptive attributes and child clusters were used as the independent and dependent variables, respectively. Objects located closer together on the plot are more correlated. $\mathrm{R}^{2} \mathrm{Y}=39 \%, 21 \% ; \mathrm{R}^{2} \mathrm{X}=$ $65 \%, 17 \%$.

sour by the descriptive panel, as shown in Fig. 4. This cluster reacted strongly to the Minneola. However, for the larger cluster of children, sweetness and sourness were not the only factors. They were not deterred as much as the other group of children by the strong acidity of the tangelo sample. These consumers required a balance between these attributes, with firm fruit flesh contributing to a positive sensory experience, as shown by their location in Fig. 7. Interestingly, the children in cluster 1 were significantly older $\left(P \leq 0.05\right.$ by $\chi^{2}$ test $)$ than the children in cluster 2, with an average age of 9.9 and 9.3 years, respectively. Past research has found that sour taste is innately distasteful (Steiner, 1977). It seems possible that the younger children had fewer exposures to sour citrus fruits and rejected the Minneola based on the novelty and intensity of this sample.

Of the samples tested for chemical measurements, the Minneola had the numerically highest SSC (Table 4) even though it clearly had the lowest perceptible sweetness value, as confirmed by both the adult consumers (Table 5) and descriptive panels (Table 3). The relatively high acidity of the fruit clearly masked the sweetness, which can be attributed to mixture effects (Bonnans and Noble, 1993; Lawless and Heymann, 2010; Pelletier et al., 2004; Schifferstein and Frijters, 1990). Although only five samples were tested for icantly between the tested samples as evaluated by the descriptive panel. Past research has had difficulty defining mandarin and orange flavors, and chemical analysis has been inconclusive to define the aroma in terms of a single or group of impact compounds (Miyazaki et al., 2012; Obenland et al., 2009; Tietel et al., 2011; Yu et al., 2017). This research used a sample of mandarin essential oil to provide a standard for the descriptive panel to rate mandarin aroma. Aromas of each variety of mandarins differ (Yu et al., 2017) and there does not seem to be any single or group of impact compounds that define the aroma. Despite this, the descriptive panel found that some samples were notably higher in perceived mandarin aroma. The samples they found highest in mandarin aroma were the Clementines and Murcotts, the most popular commercial varieties. In terms of consumer acceptance, mandarin aroma seemed to drive the preferences of many consumers, including adult cluster 2 and child cluster 1, as shown in Figs. 6 and 7. The other significant aroma attribute, pine, was not important in the statistical models. A thorough analysis of descriptive analysis for a larger number and variety of mandarins may be required to elucidate consumer perception and preference for aromas, including mandarin. More research is needed to confirm that is a desirable flavor property and how it could be increased in marketed samples throughout the growing season.

This research was conducted to determine if consumers of California mandarins differ in their preferences for commercially available mandarins. As processing and storage have major effects on the flavor of citrus (Goldenberg et al., 2015; Hagenmaier, 2002; Mannheim and Soffer, 1996; Tietel et al., 2012, 2010), research with true commercial samples and average consumers is lacking. Overall, the consumer sentiment regarding the fruit was positive. Consumer liking of the fruit was centered around their liking of the taste/flavor, with high correlations between OL, liking of flavor, and texture. These correlations may be attributed to the halo effect (Lawless and Heymann, 2010), a property where distinct attributes are rated higher because a consumer likes the product overall. As for the appearance of the fruit, importance is less clear. The consumers were first asked how much they liked the appearance of the product before tasting it and provided an unbiased assessment of the look before evaluating. The weaker correlations between appearance and OL suggest that appearance does not strongly drive how much they like the mandarins overall. Appearance, if quite poor, likely does matter but the appearance of the fruit tested here was good. Past work with Satsumas has found that blemishes, price, and seeds all play an important role in the desirability of the fruit (Campbell et al., 2004); however, this research did not inquire about the importance of good flavor. Evidence presented here urges high-quality producers and grocers to work together to provide tasting samples of the fruit or 
additional information, such as the sugar and acid measurements from the lot for the consumers. Sampled measurements, accompanied through descriptive language such as "tart," "tangy," "lemon-lime," or "lowacid" could key consumers in to fruit that they prefer. This would encourage consumers to repeatedly purchase fruit that is the best fit for them. However, with produce often sold generically, this is unlikely to happen. A combination of good farming practices, beneficial postharvest practices (including cold storage), and branding may help to clue consumers to fruit from preeminent producers. Any weaknesses in the supply chain could disrupt the ability of consumers to either find or receive high-quality fruit. High standards may, therefore, require auditing by the packing house by periodic, random testing at retailers.

There is a notable lack of consumer testing that has been performed on California commercial mandarins. Because of the high economic value of the crop in California, mapped consumer testing can allow for determination of the main drivers that predict consumer liking. This study has confirmed that California consumers react similarly to those of other geographic locations, in which juiciness, sourness, and sweetness are important properties of mandarins (Goldenberg et al., 2015; Tietel et al., 2011), but relative intensities of these attributes differed by cluster. Consumer segmentation allowed for enlightened consumer insight, a technique that may help to contextualize past research and improve citrus for consumers in the future.

\section{Literature Cited}

Bonnans, S. and A.C. Noble. 1993. Effect of sweetener type and of sweetener and acid levels on temporal perception of sweetness, sourness and fruitiness. Chem. Senses 18:273-283.

Campbell, B.L., R.G. Nelson, R.C. Ebel, W.A. Dozier, J.L. Adrian, and B.R. Hockema. 2004. Fruit quality characteristics that affect consumer preferences for satsuma mandarins. HortScience 39:1664-1669.

Campbell, B.L., R.G. Nelson, R.C. Ebel, W.A. Dozier, J.H. Campbell, and F.M. Woods. 2008. Mandarin market segments based on consumer sensory evaluations. J. Food Distrib. Res. 39:43-54.

Carbonell, L., J.L. Navarro, L. Izquierdo, and I. Carbonell. 2008. Sensory profile of mandarin chilled juices and consumers' acceptability. Rev. Agaroquimica Tecnol. Aliment. 14:157166.

Daillant-Spinnler, B., H.J.H. MacFie, P.K. Beyts, and D. Hedderley. 1996. Relationships between perceived sensory properties and major preference directions of 12 varieties of apples from the Southern Hemisphere. Food Qual. Prefer. 7:113-126.

Davis, P.L. and R.C. Hofmann. 1973. Effects of coatings on weight loss and ethanol buildup in juice of oranges. J. Agr. Food Chem. 21:455-458.
De Graaf, C. and E.H. Zandstra. 1999. Sweetness intensity and pleasantness in children, adolescents, and adults. Physiol. Behav. 67:513520.

Delgado, C. and J-X. Guinard. 2011. How do consumer hedonic ratings for extra virgin olive oil relate to quality ratings by experts and descriptive analysis ratings? Food Qual. Prefer. 22:213-225.

Desor, J.A., L.S. Greene, and O. Maller. 1975. Preferences for sweet and salty in 9-to 15-yearold and adult humans. Science 190:686-687.

Ferguson, L. and E.E. Grafton-Cardwell. 2014 Citrus production manual. 1st ed. UCANR Publ., Richmond, CA.

Goldenberg, L., Y. Yaniv, T. Kaplunov, A. DoronFaigenboim, N. Carmi, and R. Porat. 2015. Diversity in sensory quality and determining factors influencing mandarin flavor liking. J. Food Sci. 80:S418-S425.

Goldenberg, L., Y. Yaniv, T. Kaplunov, A. DoronFaigenboim, R. Porat, and N. Carmi. 2014. Genetic diversity among mandarins in fruitquality traits. J. Agr. Food Chem. 62:49384946.

Guinard, J-X. 2000. Sensory and consumer testing with children. Trends Food Sci. Technol. 11:273-283

Hagenmaier, R.D. 2002. The flavor of mandarin hybrids with different coatings. Postharvest Biol. Technol. 24:79-87.

Jordan, R.B., R.J. Seelye, and V.A. McGlone 2001. A sensory-based alternative to brix/acid ratio. Food Technol. 55:36-44.

Kim, M.K., Y-J. Lee, H.S. Kwak, and M. Kang. 2013. Identification of sensory attributes that drive consumer liking of commercial orange juice products in Korea. J. Food Sci. 78:S1451S1458.

King, E.S., H. Hopfer, M.T. Haug, J.D. Orsi, H. Heymann, G.M. Crisosto, and C.H. Crisosto. 2012. Describing the appearance and flavor profiles of fresh fig (Ficus carica L.). Cultivars. J. Food Sci. 77:S419-S429.

Kühn, B.F. and A.K. Thybo. 2001. The influence of sensory and physiochemical quality on Danish children's preferences for apples. Food Qual. Prefer. 12:543-550.

Lawless, H.T. and H. Heymann. 2010. Sensory evaluation of food: Principles and practices, Food science text series. Springer, New York, NY.

Mannheim, C.H. and T. Soffer. 1996. Permeability of different wax coatings and their effect on citrus fruit quality. J. Agr. Food Chem. 44:919923.

Martens, M. and H. Martens. 1986. Partial least squares regression. Stat. Proc. Food Res. 293359

Miyazaki, T., A. Plotto, E.A. Baldwin, J.I. ReyesDe-Corcuera, and F.G. Gmitter, Jr. 2012. Aroma characterization of tangerine hybrids by gas-chromatography-olfactometry and sensory evaluation. J. Sci. Food Agr. 92:727-735

Mourão Filho, F.de.A.A., E. Espinoza-Núñez, E.S., Stuchi, and E.M.M. Ortega. 2007. Plant growth, yield, and fruit quality of 'Fallglo' and 'Sunburst' mandarins on four rootstocks. Scientia Hort. 114:45-49.
National Agricultural Statistics Service (NASS). 2017. Citrus fruits 2017 summary. USDA, NASS, Washington, D.C

Obenland, D., S. Collin, B. Mackey, J. Sievert, and M.L. Arpaia. 2011. Storage temperature and time influences sensory quality of mandarins by altering soluble solids, acidity and aroma volatile composition. Postharvest Biol. Technol. 59:187-193.

Obenland, D., S. Collin, B. Mackey, J. Sievert, K. Fjeld, and M.L. Arpaia. 2009. Determinants of flavor acceptability during the maturation of navel oranges. Postharvest Biol. Technol. 52:156-163.

Pelletier, C.A., H.T. Lawless, and J. Horne. 2004. Sweet-sour mixture suppression in older and young adults. Food Qual. Prefer. 15:105116.

Peryam, D.R. and F.J. Pilgrim. 1957. Hedonic scale method of measuring food preferences. Food Technol. 11:9-14.

Pliner, P. and K. Hobden. 1992. Development of a scale to measure the trait of food neophobia in humans. Appetite 19:105-120.

Plotto, A., E. Baldwin, G. McCollum, J. Manthey, J. Narciso, and M. Irey. 2010. Effect of liberibacter infection (Huanglongbing or "Greening" disease) of citrus on orange juice flavor quality by sensory evaluation. J. Food Sci. 75: S220-S230.

Qannari, E.M., E. Vigneau, P. Luscan, A.C. Lefebvre, and F. Vey. 1997. Clustering of variables, application in consumer and sensory studies. Food Qual. Prefer. 8:423-428.

Rothman, L. and M. Parker. 2009. Just about right (JAR) scales: Design, usage, benefits, and risks. ASTM International, West Conshohocken, PA. Schifferstein, H.N. and J.E. Frijters. 1990. Sensory integration in citric acid/sucrose mixtures. Chem. Senses 15:87-109.

Steiner, J.E. 1977. Facial expressions of the neonate infant indicating the hedonics of foodrelated chemical stimuli. Taste Dev. Genes. Sweet Prefer. 173-188.

Tietel, Z., E. Bar, E. Lewinsohn, E. Feldmesser, E. Fallik, and R. Porat. 2010. Effects of wax coatings and postharvest storage on sensory quality and aroma volatile composition of 'Mor' mandarins. J. Sci. Food Agr. 90:9951007

Tietel, Z., E. Lewinsohn, E. Fallik, and R. Porat. 2012. Importance of storage temperatures in maintaining flavor and quality of mandarins. Postharvest Biol. Technol. 64:175-182.

Tietel, Z., A. Plotto, E. Fallik, E. Lewinsohn, and R. Porat. 2011. Taste and aroma of fresh and stored mandarins. J. Sci. Food Agr. 91:14-23.

Williams, E.J. 1949. Experimental designs balanced for the estimation of residual effects of treatments. Austral. J. Chem. 2:149-168.

Yu, Y., J. Bai, C. Chen, A. Plotto, E.A. Baldwin, and F.G. Gmitter. 2017. Comparative analysis of juice volatiles in selected mandarins, mandarin relatives and other citrus genotypes. J. Sci. Food Agr. 98:1124-1131.

Zandstra, E.H. and C. de Graaf. 1998. Sensory perception and pleasantness of orange beverages from childhood to old age. Food Qual. Prefer. 9:5-12. 